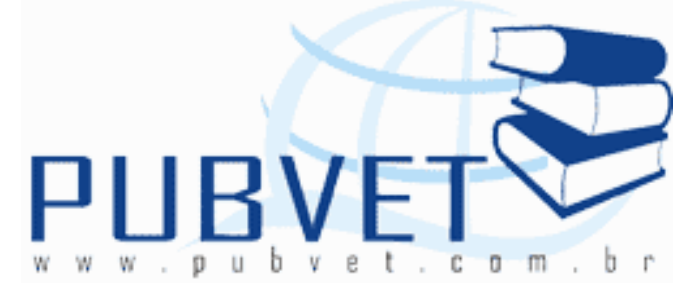

PUBVET, Publicações em Medicina Veterinária e Zootecnia.

\title{
Avaliação da perda de peso em meias-carcaças bovinas submetidas ao sistema de resfriamento por aspersão
}

\section{Aline Leite Dias ${ }^{1}$ e Pedro Alexandre Gomes Leite ${ }^{2}$}

${ }^{1}$ Graduanda em Medicina Veterinária na Universidade Estadual de Santa Cruz (UESC).

${ }^{2}$ Graduado em Medicina Veterinária (UESC), mestre em Zootecnia (UFV) e docente do Departamento de Ciências Agrárias e Ambientais (UESC).

\section{Resumo}

Devido à constante busca por melhorias no processo tecnológico de produção de carne, implantou-se recentemente no Brasil um sistema de resfriamento utilizando aspersão de água nas meias-carcaças para reduzir custos de produção, aumentar rendimentos e melhorar a qualidade da carne. Assim, objetivou-se com este trabalho estimar a perda de peso em carcaças submetidas ao resfriamento com sistema de aspersão. Foram avaliadas as porcentagens de perdas de peso em 780 meias-carcaças por um período dez meses. Após análise dos dados, observou-se valor médio de perda de 1,54\%, sendo eficiente em reduzir as perdas de peso por evaporação. Os resultados comprovaram a eficiência do sistema de aspersão em reduzir essa perda durante o resfriamento, entretanto, existe a possibilidade de aumento de peso das meias-carcaças.

Palavras-chave: aspersão em carcaças; evaporação; resfriamento. 


\title{
Carcass weight loss in bovine submitted to spray-chilling system
}

\begin{abstract}
Due to the constant search for improvements in the technological process of production of meat, it was implemented in Brazil recently the spray-chilling system in half-carcasses to reduce production costs, increase revenues and improve meat quality. Therefore, the object this study was to estimate the loss of weight in carcasses submitted to the spray-chilling. It was evaluated the percentage of loss in 780 half-carcasses for a period ten months. After data analysis, there was observed the mean value of $1.54 \%$ being effective in reducing the weight loss through evaporation. The results proved the efficiency of the spray-chilling system in reducing weight loss during cooling, and may also cause weight gain of half carcasses.
\end{abstract}

Keywords: spray-chilling, evaporation, cooling

\section{INTRODUÇÃO}

A carne fresca devido a sua atividade enzimática e elevada atividade de água, é um alimento perecível, portanto, necessita da aplicação de procedimentos de conservação e armazenamento imediatamente após o abate. Dentre os métodos mais adotados para prolongar a sua vida útil, o emprego da refrigeração tem sido o mais utilizado. A carne fresca deve ser mantida à baixas temperaturas de resfriamento (ROÇA, 2003; PEREDA et al., 2005).

O resfriamento de carcaças é utilizado para retardar as reações químicas e a atividade enzimática, desacelerando ou até mesmo inibindo o crescimento dos micro-organismos. Desta forma, quanto mais baixa a temperatura, mais pronunciado esse efeito (PRATA; FUKUDA, 2001).

Segundo Pardi et al. (2001), o processo convencional de resfriamento de carcaças bovinas é realizado com ventilação forçada, por um período de 24 horas, promovendo uma perda de peso ao resfriamento, denominada "quebra 
DIAS, A.L. e LEITE, P.A.G. Avaliação da perda de peso em meias-carcaças bovinas submetidas ao sistema de resfriamento por aspersão. PUBVET, Londrina, V. 7, N. 23, Ed. 246, Art. 1625, Dezembro, 2013.

de frio", que é provocada pela evaporação da água das carcaças. Durante este período pode haver até $2,5 \%$ de perda de peso por carcaça. Roça (2003) afirma que este processo convencional é realizado com a temperatura da câmara mantida entre 0 a $4^{\circ} \mathrm{C}$, sendo que as carcaças bovinas atingem $10^{\circ} \mathrm{C}$ em 24 horas e entre 0 a $4^{\circ} \mathrm{C}$ em 48 horas.

A velocidade de refrigeração de uma carcaça dependerá de vários fatores: calor específico da carcaça, peso, quantidade de gordura externa, condutividade térmica, temperatura da câmara de refrigeração e velocidade de circulação de ar. O calor específico é diretamente proporcional á relação de carnes magra e gorda da carcaça. A gordura reduz a dissipação de calor. Quanto maior o peso da carcaça e maior cobertura de gordura, maior será o tempo de resfriamento. A perda de peso das carcaças magras e de menor tamanho é maior do que as carcaças maiores e com boa cobertura de gordura (ROÇA, 2003).

Segundo Landim (2005), a espessura de gordura subcutânea é fundamental no processo de resfriamento da carcaça. A falta de gordura de cobertura permite uma perda excessiva de água, ocasionando perda de peso e escurecimento da carne durante o resfriamento. De acordo com a idade e o sexo do animal, observa-se diferentes proporções de músculo, gordura e osso.

Mesquita et al. (2003), afirmam que o tamanho, quantidade de gordura das carcaças, duração dos ciclos e o tempo total de duração da aspersão são determinantes da taxa de redução da perda de peso.

Segundo James (1996), no sistema convencional de resfriamento, a perda de peso por evaporação, durante as primeiras 24 horas, é em média $2 \%$. Jones; Robertson (1988) citam perdas de peso durante o resfriamento com variação de $0,75 \%$ a $2 \%$ na América do Norte, e de $1,2 \%$ a $1,7 \%$ no Reino Unido.

A busca contínua por melhorias nas características da carne e nos seus processos de fabricação é de extrema importância, tanto para obter vantagens no mercado, quanto para a qualidade da carne oferecida ao consumidor final. 
DIAS, A.L. e LEITE, P.A.G. Avaliação da perda de peso em meias-carcaças bovinas submetidas ao sistema de resfriamento por aspersão. PUBVET, Londrina, V. 7, N. 23, Ed. 246, Art. 1625, Dezembro, 2013.

Empresas de grande porte têm trazido para o Brasil tecnologias que permitam alcançar tal objetivo.

Alguns matadouros-frigoríficos bovinos usam água resfriada na pulverização das superfícies de carcaças, de forma intermitente, durante as horas iniciais de resfriamento pós-morte (ALLEN et al., 1987). A aspersão de carcaças bovinas, conhecida também como spray chilling, tem sido utilizada nos Estados Unidos e Canadá desde 1987 (JONES; ROBERTSON, 1988).

$\mathrm{O}$ processo de resfriamento com aspersão de água apresenta alguns benefícios práticos e imediatos como diminuição rápida de temperatura superficial da meia-carcaça através da água resfriada aspergida e, consequentemente, redução da evaporação e choque térmico entre a carcaça e a temperatura ambiente. Além disso, o resfriamento superficial da carcaça impede o crescimento microbiano na sua superfície. Entretanto, o maior objetivo industrial na implantação do sistema é a redução da perda de peso das carcaças (ALLEN et al., 1987).

No Brasil, apesar de ter sido autorizado e regulamentado pela Resolução No 02 de 9 agosto de 2011, instituída pelo Ministério da Agricultura, Pecuária e Abastecimento (MAPA), que define os critérios para o uso do sistema de aspersão de meias-carcaças bovinas no Brasil, os estudos sobre esse tema são escassos.

Um dos critérios instituídos pela resolução No 02, de 9 agosto de 2011 do MAPA que regulamenta o sistema de aspersão no Brasil, estabelece que o frigorífico interessado, através de um Plano de Controle de Aspersão de Carcaças (PCAC), assegure que o conjunto de meias-carcaças submetidas à aspersão de carcaças durante o processo de resfriamento não apresente ganho de peso, evitando assim a fraude econômica (BRASIL, 2011).

Segundo a mesma resolução, caso o peso "frio" exceda o peso "quente", o estabelecimento deve identificar a causa do desvio, promover o destino apropriado aos lotes acometidos, estendendo o resfriamento sem aspersão até a perda do excesso absorvido, além de paralisar as operações de aspersão até que o sistema seja ajustado e após as correções das causas, reiniciar os ciclos 
DIAS, A.L. e LEITE, P.A.G. Avaliação da perda de peso em meias-carcaças bovinas submetidas ao sistema de resfriamento por aspersão. PUBVET, Londrina, V. 7, N. 23, Ed. 246, Art. 1625, Dezembro, 2013.

de testes para fins de reavaliação dos protocolos dos ciclos de aspersão propostos (BRASIL, 2011).

Objetivou-se com este trabalho estimar a perda de peso em meiascarcaças submetidas ao sistema de resfriamento com aspersão, num frigorífico sob Inspeção Federal.

\section{MATERIAIS E MÉTODOS}

Este estudo foi desenvolvido em um matadouro frigorífico sob Inspeção Federal seguindo as normas preconizadas pelo Regulamento da Inspeção Industrial e Sanitária de Produtos de Origem Animal - RIISPOA (BRASIL, 1997). Foram avaliadas 780 meias-carcaças num período compreendido entre junho de 2012 a março de 2013. Os dados foram coletados das Planilhas de Verificação do Programa de Controle do Sistema de Aspersão - PCAC fornecidas pelo Serviço de Inspeção Federal - SIF local, onde se avalia semanalmente a porcentagem de evaporação das carcaças.

Após o abate, as meias-carcaças foram pesadas utilizando uma balança digital a qual registra o peso através de um sistema computadorizado, obtendo-se $o$ peso das meias-carcaças quentes (PCQ) e posteriormente conduzidas às câmaras de resfriamento. O tempo total de resfriamento variou entre $48 \mathrm{~h}$ e $96 \mathrm{~h}$, dependendo da lotação e temperatura da câmara, a qual foi ajustada com temperatura entre $2,1^{\circ} \mathrm{C}$ a $4^{\circ} \mathrm{C}$, e ventilação com velocidade de circulação do ar de aproximadamente $0,5 \mathrm{~m} / \mathrm{s}$.

O sistema de aspersão é dotado de tubos de PVC, contendo bicos aspersores dispostos paralelamente aos trilhos das câmaras de resfriamento, que fazem a aspersão intermitente de água clorada (máximo 1 ppm de cloro), à $2^{\circ} \mathrm{C}$ sobre as carcaças (PRADO; FELÍCIO, 2005). Empregou-se o sistema de aspersão de água em ciclos intermitentes de setenta e cinco segundos de duração e intervalos de nove minutos, durante as primeiras três horas de resfriamento, programado por um sistema automatizado. 
Após o resfriamento, as meias-carcaças foram pesadas para obtenção do peso das meias-carcaças frias (PCF). O percentual de perda ao resfriamento (PPR) foi calculado através da fórmula: PPR=(PCQ-PCF)/PCQ X 100 (OLIVEIRA et al., 2002), e também foram calculadas as médias, desvios padrão, erros padrão e porcentagens das variáveis estudadas.

\section{RESULTADOS E DISCUSSÃO}

Após análise dos dados observou-se que a perda de peso ao resfriamento do matadouro frigorífico estudado, utilizando-se o sistema de aspersão, foi de $1,54 \%$, com erro padrão igual 0,03 . Entretanto, 2,91\% das amostras apresentaram um ganho de peso com valor médio de 1,51\%.

Prado et al. (2007) testaram o sistema de aspersão em Goiás, usando ciclos intermitentes de trinta segundos de duração e intervalos entre ciclos de dez minutos, durante as primeiras seis horas de resfriamento e obteve valor médio de $0,03 \%$ de evaporação das carcaças, resultando em uma redução média de perda de peso de 1,63 ponto percentual em relação ao sistema convencional $(1,66 \%)$.

Em trabalho similar, Prado; Felício (2010) observaram uma perda de peso no sistema convencional de $1,67 \%$ e para o sistema com aspersão de água de $-0,28 \%$, evidenciando ganho de peso. O tempo de resfriamento foi de $48 \mathrm{~h}$, com velocidade de circulação de ar de $2.0 \mathrm{~m} / \mathrm{s}$ e temperatura da câmara de $0^{\circ} \mathrm{C}$, utilizando a aspersão nas seis primeiras horas com ciclos intermitentes de 30 segundos de duração e intervalos de 10 minutos entre os ciclos. Segundo os autores, o sistema é muito eficaz na prevenção da perda de peso através de evaporação, entretanto, dependendo de como os ciclos de aspersão estão programados, em vez de perder, as carcaças podem ganhar peso por absorção de água.

Este estudo demonstra que utilizando o sistema de aspersão, é possível reduzir as perdas por evaporação. Por se tratar de um sistema novo para a realidade brasileira, esperam-se melhorias para os frigoríficos que venham 
empregar esta tecnologia, com ajustes das receitas e melhoramento estrutural das câmaras frigoríficas.

Mesquita et al. (2003), em suas pesquisas no Brasil, em carcaças resfriadas com sistema de aspersão obtiveram redução de perda de peso por evaporação de 0,39\% e 1,39\% em dois frigoríficos diferentes, utilizando ciclos de 90 segundos com intervalos de 30 minutos durante as quatro primeiras horas de resfriamento.

Quando comparado com os trabalhos realizados por Mesquita et al. (2003), Prado et al. (2007), Prado; Felício (2010), o resultado deste estudo apresentou valor médio de quebra de frio bem maior, obtendo menos vantagens econômicas. Contudo, o lucro ainda é significativo, quando se compara com as perdas usuais do sistema convencional. O uso de aspersão por um tempo mais prolongado também pode ser o motivo de melhores resultados.

A variação de perda de peso ao resfriamento encontrada na literatura se dá devido às diferentes condições de estudo, como velocidade de resfriamento, duração dos ciclos e tempo total de duração da aspersão.

A alta perda de peso ao resfriamento deste estabelecimento representa uma segurança maior com relação à fraude ao consumidor. Apesar de a legislação não estabelecer um valor mínimo, restringindo-se apenas a denominar fraude econômica o ganho de peso das meias-carcaças. Quando os valores são baixos, muito próximos de zero, aumenta-se a probabilidade de ocorrência de ganho de peso das meias-carcaças.

\section{CONCLUSÕES}

Os resultados comprovam que o sistema de aspersão reduz a perda de peso durante o resfriamento, entretanto, existe a possibilidade de provocar aumento de peso de algumas das meias-carcaças. Em virtude disso, é necessário um aperfeiçoamento estrutural e organizacional além de um 
DIAS, A.L. e LEITE, P.A.G. Avaliação da perda de peso em meias-carcaças bovinas submetidas ao sistema de resfriamento por aspersão. PUBVET, Londrina, V. 7, N. 23, Ed. 246, Art. 1625, Dezembro, 2013.

perfeito ajuste do tempo total e dos ciclos da aspersão para prevenir o ganho de peso e melhorar os resultados.

\section{REFERÊNCIAS}

ALLEN, D. M.; HUNT, M. C.; LUCHIARI FILHO, A.; DANLER, R. J.; GOLL, S. J. Effects of spray chilling and carcass spacing on beef carcass cooler shrink and grade factors. Journal of Animal Science, Manhattan: Kansas State University, v. 64, p.165-170, 1987.

BRASIL. Ministério da Agricultura, Pecuária e Abastecimento (MAPA). Regulamento da Inspeção Industrial e Sanitária de Produtos de Origem Animal (RISPOA). Dispõe sobre a inspeção industrial e sanitária dos produtos de origem animal. Brasília: Ministério da Agricultura, Pecuária e Abastecimento, 1997.

BRASIL. Ministério da Agricultura, Pecuária e Abastecimento (MAPA). Resolução No 02 de 9 agosto de 2011. Dispõe sobre os critérios para o uso do sistema de aspersão de meiascarcaças bovinas no Brasil. Brasília: Ministério da Agricultura, Pecuária e Abastecimento, 2011.

JAMES, S. The chill chain from "carcass to consumer". Meat Science, v. 43, n. S, p. S203S216, 1996. Apud PRADO, C.S.; DE FELÍCIO, P.E; "INFLUÊNCIA DO MÉTODO DE RESFRIAMENTO DE CARCAÇAS BOVINAS NAS VARIAÇÕES DE PESO E NAS MEDIDAS FÍSICO-QUÍMICAS, SENSORIAIS E MICROBIOLÓGICAS DO CONTRAFILÉ (m. Longissimus dorsi)". Tese (Doutorado em Tecnologia de alimentos)-Unicamp, Campinas/SP: 2005.

JONES, S.D.M.; ROBERTSON, W.M. The effects of spray-chilling carcasses on shrinkage and quality of beef. Meat Science, s/I, v.24, p.177-188, 1988.

LANDIM, Aline Vieira. Desempenho e qualidade de carcaça em ovinos cruzados no Distrito Federal. 2005. xvi, 81 f. Dissertação (Mestrado em Ciências Agrárias), Brasília: Universidade de Brasília, 2005.

MESQUITA, A.J.; PRADO, C.S.; BUENO, V.F.F.; MANSUR, J.R.G.; NEVES, R.B.S.; NUNES, I.A.; LAGE, M.E.; OLIVEIRA, A.N. The effects of spray-chilling associated to conventional chilling on mass loss, bacteriologycal and physico-chemical quality of beef carcass. Ciência Animal Brasileira, Goiânia/GO, Editora da UFG, v. 4, n. 2, p.145-153, 2003.

OliveirA, M. V. M.; PÉREZ, J. R. O.; ALVES, E. L.; MARTINS, A. R. V.; LANA, R. P. Rendimento de carcaça, mensurações e peso de cortes comerciais de cordeiros Santa Inês e Bergamácia alimentados com dejetos de suínos em confinamento. Revista Brasileira de Zootecnia, Viçosa, v.31, n.3, p.1-9, maio/junho, 2002.

PARDI, M.C.;DOS SANTOS, I.F.; DE SOUZA, E.R.; PARDI, H.S.; Ciência, higiene e tecnologia da carne, Goiânia/GO, Editora da UFG, Vol. I. 2aed., 2001.

PEREDA, J.A.O. et al. Tecnologia de alimentos. Volume 2 - Alimentos de Origem Animal. Porto Alegre: Artmed, 2005. 
PRADO, C. S.; BUENO, C. P.; DE FELÍCiO, P. E.; Aspersão de água fria no início do resfriamento de carcaças bovinas e maturação da carne sobre o peso, cor e aceitação do músculo (Longissimus lumborum). Ciência Animal Brasileira, Goiânia/GO, Editora da UFG, 8(4), 841-848p., 2007.

PRADO, C.S.; DE FELÍCIO, P.E; Influência do método de resfriamento de carcaças bovinas nas variações de peso e nas medidas físico-químicas, sensoriais e microbiológicas do contrafilé ( $m$. Longissimus dorsi). Tese (Doutorado em Tecnologia de alimentos), Campinas/SP: Unicamp, 2005.

PRADO, C.S.; DE FELÍCIO, P.E. Effects of chilling rate and spray-chilling on weight loss and tenderness in beef strip loin. Meat Science, s/l,86 (2), 430-435p, 2010.

PRATA, L. F.; FUKUDA, R. T.; Fundamentos de higiene e inspeção de carnes. Jaboticabal/SP: UNESP/Funep, 2001.

ROÇA, R.O. Refrigeração. Laboratório de Tecnologia dos Produtos de Origem Animal. Fazenda Experimental Lageado - FCA. Campus de Botucatu, SP, 2003. Acesso em: 15 de maio de 2013. Disponível em: http://pucrs.campus2.br/ thompson/Roca108.pdf 